\title{
PENGUJIAN EKSISTENSI ENVIRONMENTAL KUZNETS CURVE DI INDONESIA
}

\author{
Muhammad Fajar*1, Hariyanto ${ }^{2}$ \\ 1,2 Badan Pusat Statistik Provinsi Banten \\ mfajar@bps.go.id ${ }^{* 1}$, hariyanto@bps.go.id ${ }^{2}$,
}

\begin{abstract}
The purpose of this study is to examine the existence of the environmental phenomenon Kuznets Curve $(E K C)$. The method used in this research is the quadratic regression method which is estimated by using ordinary least squares by first reconstructing the predictor variables. The data used are carbon dioxide emissions per capita (metric tonnes) sourced from the World Bank Dataset, nominal GDP (Gross Domestic Product) (thousands of Rupiah), and total population sourced from the Central Statistics Agency. The results of this study conclude that the EKC phenomenon exists in Indonesia, which is indicated by the significant coefficient of the quadratic component in the model. This implies that economic activities that use fossil fuels are increasingly being used. However, economic growth at a certain point leads to production activities, making humans aware that the environment and nature must be preserved and sustainable for the economic needs of the next generations.
\end{abstract}

Keywords: Kuznets, Carbondioxide Emission, EKC, GDP

\begin{abstract}
Abstrak
Tujuan studi adalah untuk menguji eksistensi fenomena environmental Kuznets Curve (EKC). Metode yang digunakan dalam penelitian ini adalah metode regresi kuadratik yng diestimasi dengan ordinary least square dengan terlebih dahulu merekonstruksi varibel prediktor. Adapun data yang digunakan adalah emisi karbondioksida per kapita (metrik ton) bersumber dari World Bank Dataset, PDB (Produk Domestik Bruto) nominal (ribuan Rupiah) dan jumlah penduduk yang bersumber dari Badan Pusat Statistik. Hasil penelitian ini menyimpulkan bahwa fenomena EKC eksis terjadi di Indonesia yang diindikasikan dari koefisien komponen kuadrat pada model signifikan. Ini menyiratkan bahwa aktivitas ekonomi yang menggunakan bahan bakar fosil semakin meningkat penggunaannya. Namun, pertumbuhan ekonomi pada titik tertentu yang bermuara pada aktivistas produksi, membuat manusia sadar bahwa lingkungan dan alam harus dijaga dan berkesinambungan untuk kebutuhan ekonomi generasi mendatang.
\end{abstract}

Kata kunci: Kuznets, Emisi Karbondioksida, EKC, PDB 
Jurnal Lebesgue : Jurnal Ilmiah Pendidikan Matematika, Matematika dan Statistika

Muhammad Fajar, Hariyanto

Volume 2, No. 1, April 2021 hal.62-68

DOI Artikel : 10.46306/lb.v2i1.56

\section{PENDAHULUAN}

EKC (Environmental Kuznets Curve) merupakan pengembangan dari teori Kuznets bahwa dalam jangka pendek ada korelasi positif antara pertumbuhan ekonomi dengan ketidakmerataan pendapatan masyarakat, tetapi dalam jangka panjang hubungan keduanya menjadi korelasi yang negatif (Kuznets, 1955). Artinya, dalam jangka pendek meningkatnya pendapatan nasional akan diikuti dengan meningkatnya ketidakmerataan pendapatan, tetapi dalam jangka panjang peningkatan pendapatan nasional akan diikuti dengan penurunan ketidakmerataan pendapatan. Sehingga, hubungan kedua variabel tersebut jika divisualkan seperti kurva $U$ terbalik. Atas dasar tersebut dapat dibentuk pemikiran dengan analogi yang sama, yaitu bahwa pertumbuhan ekonomi pada tahap-tahap awal pembangunan menyebabkan degrdasi lingkungan sampai pada titik pendapatan tertentu. Kemudian, semakin meningkatnya pendapatan maka kebutuhan kualitas lingkungan yang lebih baik semakin meningkat seiring meningkatnya pendapatan nasional (Shafik dan Bandyopadhyay,1992; Grossman dan Krueger, 1991, 1995; Panayotou, 1994; Shafik, 1994; Selden dan Song,1994).

Penyelidikan empiris tentang EKC dilakukan dengan melihat pemodelan dan signifikansinya dari bentuk hubungan antara degradasi lingkungan dan pendapatan nasional. Beberapa studi menunjukkan bahwa hubungan kedua variabel tersebut memiliki hubungan linier (Shafik dan Bandyopadhyay,1992; Roca et al.,2001; York et al. 2003; Azomahou et al., 2006; Lise, 2006). Studi lainnya melaporkan bahwa model dari bentuk hubungan kedua variabel tersebut jika divisualkan seperti kurva U terbalik/model kuadratik (Cole et al.,1997; Agras dan Chapman, 1999; Galeotti dan Lanza, 1999; Heil dan Selden,2001; Cole, 2004; Galeotti et al., 2006; Sirag et al., 2018). Studi lainnya menyatakan bahwa EKC tidak exist (Perman and Stern, 2003; Azwar, 2019).

Menurut penulis, hipotesis EKCdapat diselidiki hanya dengan cara time series ataupun panel pada suatu Negara, asalkan data yang tersedia cukup panjang (minimal 30 titik data tahunan, jika dalam triwulanan minimal 120 titik data triwulan). Hal ini dikarenakan ide Kuznets berkaitan dengan proses pembangunan yang memerlukan waktu yang panjang sehingga fenomena dapat diuji keberadaannya. Dalam penelitian ini, penulis akan menyelidiki apakah fenomena EKC terjadi di Indonesia atau tidak. Studi kasus EKC Indonesia dipilih dengan pertimbangan bahwa: (1) dari periode 1960 hingga 2015 PDB nominal per kapita terus meningkat koherensi dengan meningkatnya emisi karbondioksida sepanjang periode observasi (lihat gambar 1.1.a dan 1.1.b), dan (2) scatter plot kedua variabel tersebut menyerupai kurva U terbalik (lihat gambar 1.1.c). 
Sistematika paper ini terbagi menjadi empat bagian, yaitu: Bagian I Pendahuluan berisi latar belakang permasalahan penelitian ini. Bagian II Metode berisi ringkasan metode dan sumber data yang digunakan dalam penelitian ini. Bagian III Hasil dan Pembahasan berisi pembahasan mengenai hasil estimasi model. Bagian IV Kesimpulan berisi kesimpulan dari paper ini.

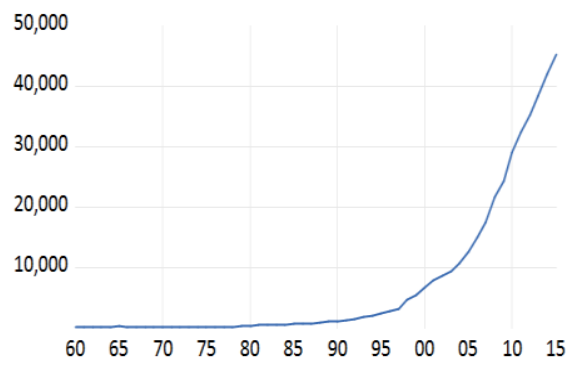

(a)

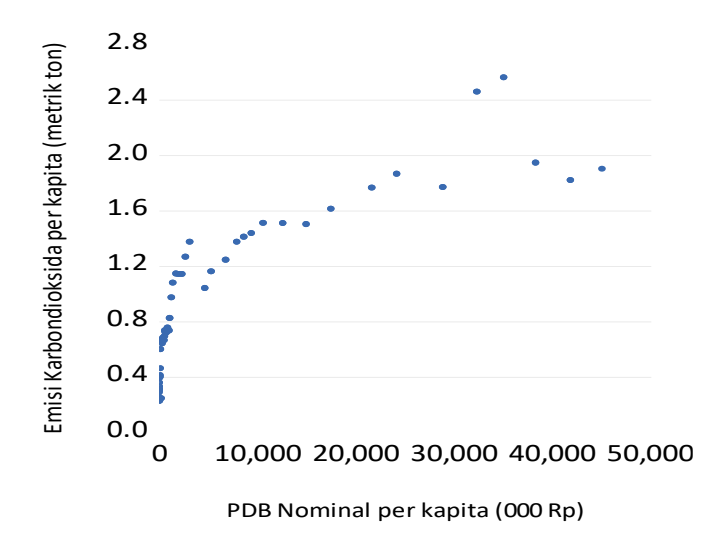

(c)

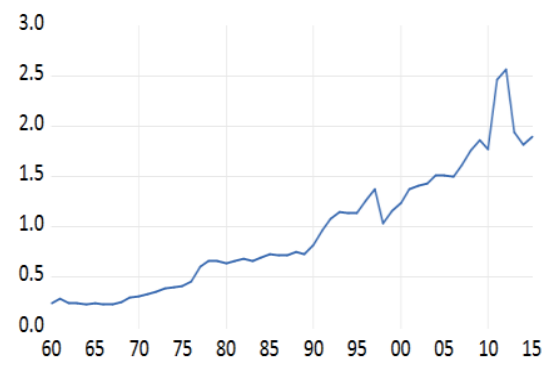

(b)

Gambar 1 (a) Perkembangan PDB Nominal per kapita Indonesia 1960 -2015 (Ribuan Rp), (b) Perkembangan Emisi Karbondioksida per kapita (metrik ton), dan (c) Scatter Plot antara PDB PDB Nominal per kapita dan PDB Nominal per kapita

\section{METODE PENELITIAN}

\section{Sumber Data}

Data yang digunakan dalam penelitian ini adalah data emisi karbondioksida per kapita sebagai proxy degradari kualitas lingkungan bersumber dari world bank dataset, PDB Nominal (Milyar Rp) dan jumlah penduduk bersumber dari Badan Pusat Statistik. Periode data yang digunakan dalam level tahunan mulai dari tahun 1960 s.d. 2015.

\section{Metode Analisis}

\section{Spesifikasi Model}

Berdasarkan gambar 1.1.c bahwa plot antara PDB Nominal per kapit dan emisi karbondioksida per kapita menyerupai kurva U terbalik, sehingga penulis mengajukan model kuadratik sebagai berikut: 
Jurnal Lebesgue : Jurnal Ilmiah Pendidikan Matematika, Matematika dan Statistika

Muhammad Fajar, Hariyanto

Volume 2, No. 1, April 2021 hal.62-68

DOI Artikel : 10.46306/lb.v2i1.56

$$
Y_{t}=\delta_{0}+\delta_{1} X_{t}+\delta_{2} X_{t}^{2}+v_{t}
$$

dengan: $Y_{t}$ adalah emisi karbondioksida per kapita, $X_{t}$ adalah PDB Nominal per kapita, $v_{t}$ adalah eror random, $\delta_{0}$ adalah intersep, dan $\delta_{1}, \delta_{2}$ adalah koefisien.

Fenomena EKC dapat disimpulkan terjadi (eksis) jika model (1) secara statistik valid (ditandai nilai $\mathrm{F}$ statistik signifikan), $\delta_{1}>0$ signifikan secara statistik (ditandai nilai $\mathrm{t}$ statistik signifikan), $\delta_{2}>0$, signifikan secara statistik (ditandai nilai $t$ statistik signifikan).

\section{Metode Regresi}

Model (1) direkonstruksi menjadi bentuk:

$$
Y_{t}=\delta_{0}+\delta_{1} Z_{1 t}+\delta_{2} Z_{2 t}+v_{t}
$$

dengan: $X_{t}=Z_{1 t}, X_{t}^{2}=Z_{2 t}$, dan $t=1, \ldots, T$. Dari model/persamaan (2) diubah menjadi bentuk persamaan matriks, sebagai berikut:

$$
\boldsymbol{y}=\delta_{0} \mathbf{1}_{n}+\boldsymbol{Z} \boldsymbol{\delta}+\boldsymbol{\varepsilon}
$$

dengan: $\boldsymbol{y}$ : variabel respon $\left(Y_{1}, \ldots, Y_{T}\right), \delta_{0}$ : konstan (intersep), $\boldsymbol{\delta}$ : vektor koefisien regresi berukuran $p \times 1$,

$$
\boldsymbol{Z}=\left[Z_{1 t} \ldots Z_{2 t}\right]
$$

matriks desain berukuran $T \times p$, sebanyak $p$ variabel prediktor (dalam hal ini adalah $X_{t}=$ $Z_{1 t}$ dan $X_{t}^{2}=Z_{2 t}$ ), dan $\boldsymbol{\varepsilon}$ : vektor random eror (dalam hal ini adalah $v_{t}$ ) adalah berdistribusi i.i.d $N\left(\mathbf{0}_{n}, \sigma^{2} \boldsymbol{I}_{n}\right)$. Persamaan (3) diestimasi dengan metode least squares sehingga diperoleh estimator untuk koefisien regresi untuk persamaan (3) adalah:

$$
\widehat{\boldsymbol{\delta}}=\left(\boldsymbol{X}^{T} \boldsymbol{X}\right)^{-1} \boldsymbol{X}^{T} \boldsymbol{y}
$$

\section{HASIL DAN PEMBAHASAN}

Hasil estimasi persamaan (11) yang merupakan model EKC dengan menggunakan ordinary least squares adalah sebagai berikut:

Tabel 1 Hasil Estimasi Model (1)

\begin{tabular}{|l|c|c|c|}
\hline \multicolumn{1}{|c|}{ Koefisien } & Estimasi & t-stat & p-value \\
\hline$\hat{\delta}_{0}$ & $5.38 \times 10^{-}$ & 13.01 & 0.0000 \\
\hline$\hat{\delta}_{1}$ & 1 & 10.86 & 0.0000 \\
\hline$\hat{\delta}_{2}$ & $-1.71 \times 10^{-9}$ & -6.73 & 0.0000 \\
\hline $\mathrm{R}^{2}$-adj & 0.837775 & S.E. of regression & 0.244862 \\
\hline $\begin{array}{l}\text { Jarque-Berra Stat. Untuk normalitas } \\
\text { residual }\end{array}$ & 2.585481 & $\begin{array}{c}\text { p-value (Jarque-Berra } \\
\text { Stat.) }\end{array}$ & 0.274517 \\
\hline F-stat & 143.0181 & Sum Squared Residual & 3.177741 \\
\hline p-value (F-stat) & 0.000000 & AIC & 0.075839 \\
\hline
\end{tabular}


Tabel 1 memberikan informasi bahwa spesifikasi model yang dibentuk valid. Hal tersebut ditunjukkan dari p-value (F-stat) yang bernilai kurang 5\% (level alpha) dan residual mengikuti distribusi normal ( $p$-value dari jarque-Berra Stat.) lebih besar dari 5\%). Model (1) tersebut dapat menjelaskan $83.78 \%$ variasi pada variabel emisi karbondioksida per kapita, ini tercermin dari plot nilai prediksi variabel dependen (garis merah pada gambar 3.1) cukup fit dengan scatter plot data aktual (lihat gambar 2). Sedangkan, sisanya sebanyak $9.58 \%$ dijelaskan variabel lain di luar model (1). Semua koefisien dalam model signifikan pada level alpha 5\%, dimana $\hat{\delta}_{1}>0$ dan signifikan pada level alpha $5 \%$, serta $\hat{\delta}_{2}<0$ (bernilai negatif) dan signifikan pada level alpha $5 \%$. Atas dasar temuan tersebut dapat disimpulkan bahwa fenomena EKC eksis terjadi di Indonesia, walaupun secara visual kurva $U$ terbalik belum sempurna (Kurva U terbalik terpotong).

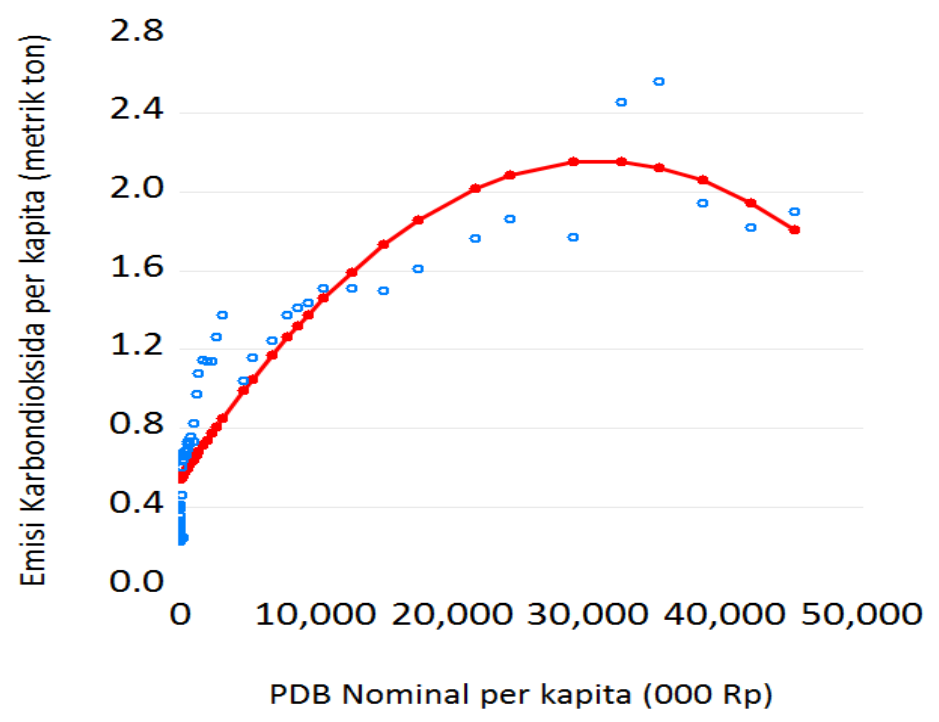

Gambar 2. Plot nilai fitted (garis merah) dari model (1)

Karena model EKC diestimasi adalah model kuadratik, maka dapat ditentukan turning point dengan menderivasikan model (1) terhadap $X_{t}$ dan di-samadengan-kan nol (0), sehingga:

$$
X_{t}=-\frac{\delta_{1}}{2 \delta_{2}}
$$

Hasil estimasi pada tabel 1 diinput pada persamaan (2) sehingga diperoleh turniing point, yaitu Rp30,701,754.4, artinya ketika PDB nominal per kapita mencapai turning point-nya, maka tinggi emisi karbondioksida per kapita juga mencapai maksimum. Namun, setelah itu emisi karbondioksida per kapita mengalami penurunan, seiring meningkatnya PDB nominal per kapita. Ini mengindikasikan bahwa pertumbuhan ekonomi Indonesia menyebabkan degradasi lingkungan, karena pertumbuhan ekonomi merupakan refleksi aktivitas ekonomi yang menggunakan bahan bakar fosil untuk transportasi, produksi manufaktur dan pembangkit 
Jurnal Lebesgue : Jurnal Ilmiah Pendidikan Matematika, Matematika dan Statistika

Muhammad Fajar, Hariyanto

Volume 2, No. 1, April 2021 hal.62-68

DOI Artikel : $10.46306 / 1 b . v 2 i 1.56$

listrik, yang sejak awal kemerdekaan hingga saat ini semakin meningkat penggunaannya. Pertumbuhan ekonomi pada titik tertentu membuat manusia sadar bahwa lingkungan dan alam harus dijaga dan berkesinambungan untuk kebutuhan ekonomi generasi mendatang. Titik inilah yang disebut turning point. Implikasinya, aktivitas ekonomi di masa mendatang akan berorientasi pada pengurangan bahan bakar fosil, seperti penggunaan energi listrik dari tenaga matahari, tenaga air, tenaga panas bumi, dan tenaga gerak mesin, serta industri 4.0 juga dapat berperan dalam menciptakan kualitas lingkungan.

\section{KESIMPULAN}

Berdasarkan pembahasan sebelumnya dapat disimpulkan bahwa fenomena EKC eksis di Indonesia. Hal ini ditunjukkan bahwa koefisien pada komponen kuadrat pada model (1) signifikan, sehingga fenomena EKC direpresentasikan dalam model kuadratik valid (kurva U terbalik). Ini berarti dalam jangka pendek meningkatnya pendapatan nasional akan diikuti dengan meningkatnya emisi karbondioksida, tetapi dalam jangka panjang peningkatan pendapatan nasional akan diikuti dengan penurunan emisi karbondioksida. Ini mengindikasikan bahwa aktivitas ekonomi yang menggunakan bahan bakar fosil semakin meningkat penggunaannya. Namun, pertumbuhan ekonomi pada titik tertentu yang bermuara pada aktivistas produksi, membuat manusia sadar bahwa lingkungan dan alam harus dijaga dan berkesinambungan untuk kebutuhan ekonomi generasi mendatang. Titik inilah yang disebut turning point.

\section{DAFTAR PUSTAKA}

Agras, Chapman, 1999. A dynamic approach to the environmental Kuznets curve hypothesis. Ecological Economics 28, 267-277

Azomahou, T., Laisney, F., Phu, N.V., 2006. Economic development and CO2 emissions: a nonparametric panel approach. Journal of Public Economics 90, 1347-1363

Azwar, 2019. Economic growth and CO2 emissions in indonesia: investigating the environmental kuznets curve hypothesis existence. Jurnal BPPK 12 (1), $42-52$

Cole, M.A., 2004. US environmental load displacement: examining consumption, regulations and the role of NAFTA. Ecological Economics 48 (4), 439-450

Cole, M.A., Rayner, A.J., Bates, J.M., 1997. The environmental Kuznets curve: an empirical analysis. Environmental and Development Economics 2, 401-416

Galeotti, M., Lanza, A., 1999. Richer and cleaner? A study on carbon dioxide emissions in developing countries. Energy Policy 27, 565-573

Galeotti, M., Lanza, A., Pauli, F., 2006. Reassessing the environmental Kuznets curve for CO2 emission: a robustness exercise. Ecological Economics 57, 152-163.

Grossman, G.M, Krueger, A.B., 1995. Economic growth and the environment. The Quarterly Journal of Economics 110 (2), 353-377. 
Grossman, G.M., Krueger, A.B., 1991. Environmental impacts of a north American free trade agreement. National Bureau of Economic Research Working Paper No. 3914, NBER, Cambridge MA.

Heil, M.T., Selden, T.M., 2001. Carbon emissions and economic development: future trajectories based on historical experience. Environment and Development Economics 6, 63-83.

Kuznets, S., 1955. Economic growth and income inequality. American Economic Review 45 (1), 1-28.

Lise, W., 2006. Decomposition of CO2 emissions over 1980-2003 in Turkey. Energy Policy $34,1841-1852$.

Panayotou, T., 1994. Empirical tests and policy analysis of environmental degradation at different stages of economic development. Pac Asian J Energ 4, $23-42$.

Perman, R., and D. I. Stern, 2003. Evidence from Panel Unit Root and Cointegration Tests that the Environmental Kuznets Curve Does Not Exist. Australian Journal of Agricultural and Resource Economics 47: 325-347.

Roca, J., Padilla, E., Farré, M., Galletto, V., 2001. Economic growth and atmospheric pollution in Spain: discussion the environmental Kuznets hypothesis. Ecological Economics 39, 85-99.

Selden, T.M., Song, D., 1994. Environmental quality and development: is there a Kuznets Curve for air pollution emissions. Journal of Environmental Economics and Management 27 (2), 147-162.

Shafik, N., 1994. Economic development and environmental quality: an econometric analysis. Oxford Econ Papers 46, 757-773.

Shafik, N., Bandyopadhyay, S., 1992. Economic growth and environmental quality. Background Paper for the 1992 World Development Report, The World Bank, Washington, DC

Shafik, N., Bandyopadhyay, S., 1992. Economic growth and environmental quality: timeseries and cross-country evidence. World Development Report Working Paper WPS 904, The World Bank, Washington, DC.

Sirag, A., Matemilola, B.T., Law, S.H., Bany-Ariffin, A.N., 2018. Does environmental Kuznets curve hypothesis exist? Evidence from dynamic panel threshold. Journal of Environmental Economics and Policy 7:2, 145-165.

York, R., Rosa, E.A., Dietz, T., 2003. STIRPAT, IPAT and ImPACT: analytic tools for unpacking the driving forces of environmental impacts. Ecological Economics 46 (3), $351-365$ 